\title{
Modeling of the Ionospheric Response to the Solar Eclipse of 24 October 1995 \\ Li-Bo Liu ${ }^{1, *}$, Wej-Xing Wan ${ }^{1}$, Jian-Nan Tu ${ }^{2}$ and Zong-Ti Bao ${ }^{3}$
}

(Manuscript received 12 January 1999, in final form 18 January 2000)

\begin{abstract}
In this paper the ionospheric effects of the solar eclipse of October 24, 1995 were investigated using a two-dimensional ionospheric theoretical model. In the calculations, only the depression of solar EUV fluxes during the course of the eclipse was taken into account under the solar eclipse condition. (1) During the period of the eclipse, the optical effects were quite clear at the lower altitudes of the ionosphere, while the responses to the eclipse were weaker, delayed, but longer in duration at the higher altitudes. (2) The lower the magnetic latitude, the stronger was the response to the solar eclipse. In low latitude regions, the values of $f_{0} F_{2}$ on the eclipse day were lower compared with those under the control conditions, whereas $h_{m} F_{2}$ values were higher. (3) Near the magnetic equator there was a sharp transition in $h_{m} F_{2}$ after the maximum phase of obscuration, and a solar $F_{1.5}$ layer appeared below the normal peak height of the $F_{2}$ layer. (4) After the maximum phase, the effects of the eclipse lasted longer near Hainan, and a secondary depression occurred over the magnetic equator. The mechanisms that may be responsible for the eclipse-caused effects are discussed here.
\end{abstract}

(Key Words: Solar eclipse, Ionospheric effects of the solar eclipse, Low latitude ionosphere, Ionospheric theoretical model)

\section{INTRODUCTION}

Solar eclipses present golden opportunities for scientists/physicians to enhance their understanding of the chemical and dynamic processes which occur in the ionosphere. Yeh et al. (1997) provide us a good explanation of the reasons that the ionospheric responses to solar

\footnotetext{
${ }^{1}$ Wuhan lonospheric Observatory, Wuhan Institute of Physics and Mathematics, Chinese Academy of Sciences, Wuhan, Hubei, 430071, P. R. China

${ }^{2}$ Department of Space Physics, Wuhan University, Wuhan, Hubei, 430072, P. R. China

${ }^{3}$ Department of Physics, South China Normal University, Guangzhou, 510631, P. R. China

* Corresponding author address: Dr. L.-B. Liu, Wuhan lonospheric Observatory, Wuhan Institute of Physics and Mathematics, Chinese Academy of Sciences, Wuhan, Hubei, 430071, P. R. China E-mail: liboliu@nmr.whcnc.ac.cn
} 
eclipses are studied and they describe some typical observations of previous solar eclipses in their paper.

On October 24, 1995 a total solar eclipse occurred with its path cutting through the low latitude region of Asia. Yeh et al. (1997) used $\mathrm{f}_{0} \mathrm{~F}_{2}$ data measured from six ionosonde stations near the $120^{\circ} \mathrm{E}$ longitude chain, while Huang et al. (1999) used TEC data (using the tomographical reconsmuction technique) at a chain of six NNSS receiving stations to study the response of the ionosphere to this solar eclipse. Some interesting effects were reported. For example, the largest depression in $\mathrm{N}_{\max }$ occurred about 1.5 hours after the maximum obscuration appeared near $14^{\circ} \mathrm{N}$ geomagnetic latitude even though the percent obscuration of the sun at lower latitudes was larger. About six hours after the maximum phase, another secondary depression in $\mathrm{N}_{\max }$ was observed for latitudes lower than $14^{\circ} \mathrm{N}$ (Yeh et al., 1997).

In this paper the ionospheric effects of the solar eclipse were investigated using a twodimensional ionospheric theoretical model. The focus was on low latitude ionospheric responses to variations in the ionization production caused by the eclipse. The calculations under the solar eclipse condition only took into account the depression of the solar EUV fluxes due to the shadow on the sun's light caused by the moon. The influence of other factors, such as plasma temperatures and vertical $\boldsymbol{E} \times \boldsymbol{B}$ drifts, are discussed in another paper. After a brief description of the low-latitude ionospheric model in Section 2, the modelling results are presented in Section 3. The discussion and conclusions are presented in Section 4.

\section{THE THEORETICAL IONOSPHERIC MODEL}

The ionospheric model used in this paper is a two-dimensional low latitude model, as has previously been described by Liu et al. (1998) and Tu et al. (1997). The concentrations and velocities of $\mathrm{O}^{+}, \mathrm{H}^{+}, \mathrm{He}^{+}, \mathrm{N}_{2}^{+}, \mathrm{O}_{2}^{+}, \mathrm{NO}^{+}$ions were calculated from the time dependent continuity and momentum equations (which are in the same form as those of Bailey and Sellek, 1990) within a chosen geomagnetic meridian plane in the model. The number density of electrons was obtained from the sum concentrations of all ion species under the assumption of charge neutrality. The plasma momentum equations included the collision couplings between ion and neutrals or ions, the diffusion along the direction of the magnetic field lines due to plasma pressure terms and gravity and the $\boldsymbol{E} \times \boldsymbol{B}$ drifts. The geomagnetic field used was a tilted dipole field, as described by Fraser-Smith (1987). An operator splitting scheme (e.g. Hewett and Langdon, 1987) was employed to process the transport equations. In the model, the ionic continuity equations were solved within a magnetic meridian plane that passes through Hainan (geographic longitude $110^{\circ} \mathrm{E}$, latitude $20^{\circ} \mathrm{N}$ ). The discrete grid points, which were fixed during the calculations, were taken as the cross points of the geomagnetic field lines and plasma drift lines. The boundary conditions at the base altitude, $130 \mathrm{~km}$, were chemical equilibrium conditions and at the uppermost points were linear extra-interpolations. The maximum height of the grid points was about $3000 \mathrm{~km}$, the maximum height step of the grids was less than 15 $\mathrm{km}$, and the influence of the boundary conditions on the $\mathrm{F}$ region was small. The calculations were run for 3 days to remove the effects of the initial conditions, and the final 24-hour data were taken for diagnostics. 
Solar EUV productions of $\mathrm{O}^{+}, \mathrm{He}^{+}, \mathrm{N}_{2}^{+}, \mathrm{O}_{2}^{+}$and about 30 chemical reactions related to those ionized species including the $4 \mathrm{~S}, 2 \mathrm{D}$ and $2 \mathrm{P}$ state divisions of the $\mathrm{O}^{+}$ion photoionization rates were taken into account. The photoionization and photoabsorption cross-sections were taken from Torr and Torr (1982), while the EUV fluxes were calculated from the EUV91 model (Tobiska, 1991). The concentrations and temperatures of the neutral species needed in the ionospheric model were provided by MSIS86 (Hedin, 1986), except for the concentration of the constituent NO which was calculated using the expression of Mitra (1968). The horizontal neutral winds were taken from HWM90 (Hedin et al., 1990), and the electron and ion temperatures were calculated from IRI90 (Biltza, 1990). The plasma vertical $\boldsymbol{E} \times \boldsymbol{B}$ drift velocities at the magnetic equator, shown in Fig. 1, were constructed from incoherent scatter radar measurements at Jicarmarca, Peru (Fejer, 1981). According to Anderson (1981), the influence of the zonal $\boldsymbol{E} \times \boldsymbol{B}$ drift on the densities of the F-layer ionosphere can be ignored. Therefore, the east-west $\boldsymbol{E} \times \boldsymbol{B}$ drift was not considered in the model. Results from the model generally agree well with measurements (Tu et al., 1997).

\section{CALCULATIONS AND RESULTS}

Atmospheric parameters on the eclipse day (October 24, 1995) were assumed to be the same as normal ones, i.e. parameters on a day with no eclipse. This assumption has been used in previous reports on the ionospheric effects during solar eclipses, e.g., Li et al. (1990) and

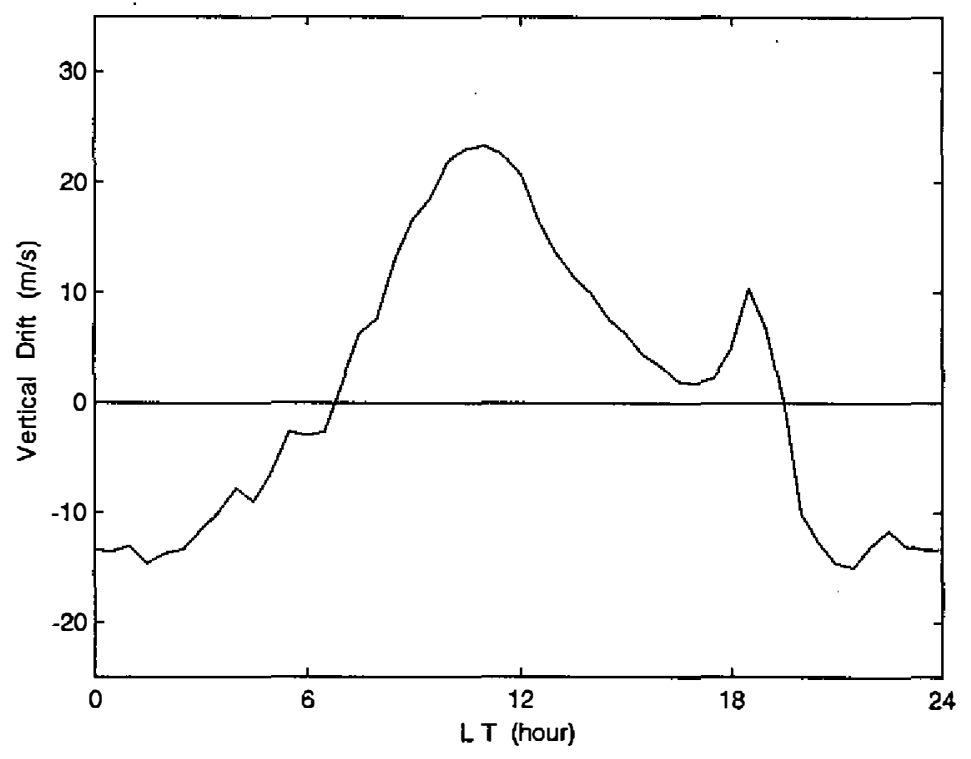

Fig. 1. Diumal variations in the equatorial plasma vertical $\boldsymbol{E} \times \boldsymbol{B}$ drift, constructed from incoherent scatter radar measurements at Jicarmarca, Peru. Positive is in the upward direction. The data are for the normal geographic condition during this eclipse period. 
Sterling and Hanson (1970). There are day-to-day variations in the ionosphere, and the above assumption is truly far from reality. However, the focus here was on the ionospheric effects of the depression of the ionic photoionization rates during the eclipse, so the assumption justifies the exclusion of the influences other factors from the calculations. In short, the calculations under the solar eclipse condition only take into account the depression of solar EUV fluxes due to the shadow effect of the eclipse; other possible changes due to the eclipse were not considered. In calculating ion production, it was assumed that solar EUV fluxes were radiated uniformly from the sun's disk, and accordingly, the ionization production rate during the eclipse, $P_{e}$, of $\mathrm{O}^{+}, \mathrm{He}^{+}, \mathrm{N}_{2}^{+}, \mathrm{O}_{2}^{+}$was:

$$
P_{e}=P_{0} E(\vec{r}, t),
$$

where $P_{0}$ is the ion photoionization rate produced by the solar EUV fluxes in the normal case, and $E(\vec{r}, t)$ as a function of time and position, is the uneclipsed fraction of the sun's disk (Van Zandt et al., 1960). The solar obscuration of this eclipse as a function of time and latitude at altitude $200 \mathrm{~km}$ is plotted in Fig. 2.

Reports on the variations in electron temperature during previous solar eclipses in the $\mathrm{F}$ region show different, even contradictory, results. To illustrate, during the eclipse of July 20, 1963, the electron temperature, observed by Millstone Hill radar, decreased by about $100 \mathrm{~K}$ at $350 \mathrm{~km}$ and by $300 \mathrm{~K}$ at $650 \mathrm{~km}$ compared to the control days (Evans, 1965). In contrast, Sterling et al. (1972) reported that during the eclipse of September 11, 1969 there was an apparent increase in temperature around 400 and $500 \mathrm{~km}$ at Jicarmarca, Peru. Another observation made by Van Zandt et al. (1960), however, indicated that temperature changes at Dan-

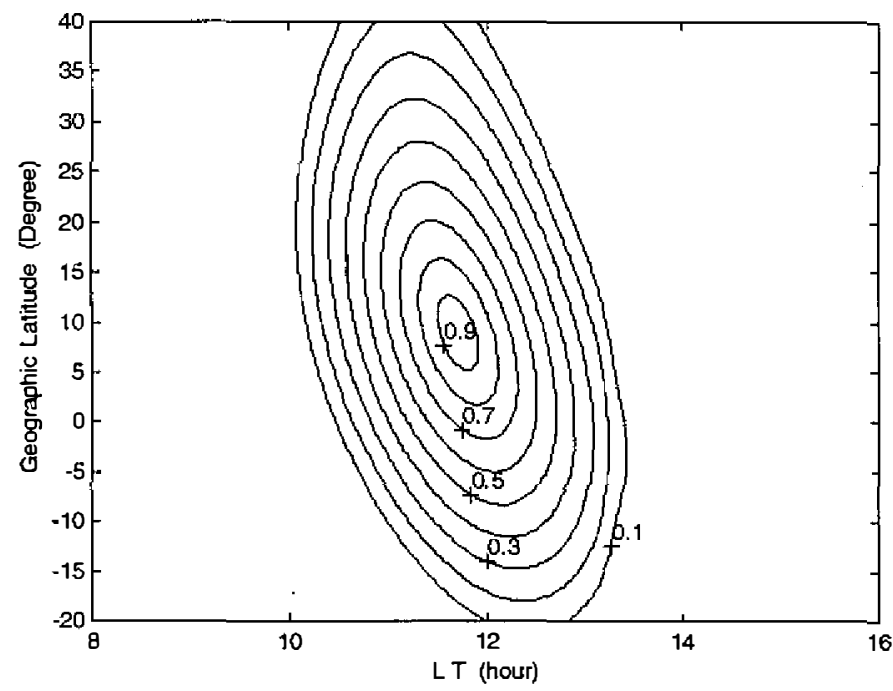

Fig. 2. Solar obscuration of the eclipse on October 24, 1995 as a function of time and geographic latitude at an altitude of $200 \mathrm{~km}$ for a geographic longitude of $110^{\circ} \mathrm{E}$. 
ger Island were probably negligible during the period of the eclipse of October 12,1958 . It is possible that the ion and electron temperature variations during the eclipse were a function of height and latitude. Unfortunately, ion and electron temperature data for the October 24, 1995 eclipse are not available. Neither are data for the vertical drift. In these calculations the vertical $\boldsymbol{E} \times \boldsymbol{B}$ drifts, ion and electron temperatures during the period of the eclipse were not adjusted. Modelling the effects of adjusting the temperature and vertical $\boldsymbol{E} \times \boldsymbol{B}$ drift show that the variations in the vertical $\boldsymbol{E} \times \boldsymbol{B}$ drift may induce far greater changes in $\mathrm{f}_{0} \mathrm{~F}_{2}$ than those caused by the variations in temperatures during an eclipse. Those results are presented in another paper.

From October 23-25, 1995, both solar activity and magnetic activity were quiet. The atmospheric parameter values taken were appropriate for this period (Solar $10.7 \mathrm{~cm}$ flux index, $\mathrm{F}_{107}=73$, its 81-day average index, $\mathrm{F}_{107 \mathrm{~A}}=77, \mathrm{Ap}=6$ ). The modelled results are presented in Figs. 3-7.

On October 24,1995 , the solar declination angle was about $-11.94^{\circ}$. Contours of calculated $\mathrm{f}_{\mathrm{o}} \mathrm{F}_{2}$ and $\mathrm{h}_{\mathrm{m}} \mathrm{F}_{2}$ at low latitudes within the given magnetic meridian on the eclipse day and on the control day are depicted in Figs. 3 and 4, while $\mathrm{f}_{0} \mathrm{~F}_{2}$ and $\mathrm{h}_{\mathrm{m}} \mathrm{F}_{2}$ as a function of local time at some specific latitudes are displayed in Fig. 5. Presented in Fig. 6 are the contours of elecron densities as a function of height and local time at these latitudes. The height profiles of the electron densities over the magnetic equator at some given times are plotted in Fig. 7.

Compared with the values of $\mathrm{f}_{0} \mathrm{~F}_{2}$ in the control case (solid lines in Fig. 3), those in the eclipse case (dotted lines) were smaller after the eclipse occurred. Near the magnetic equator,

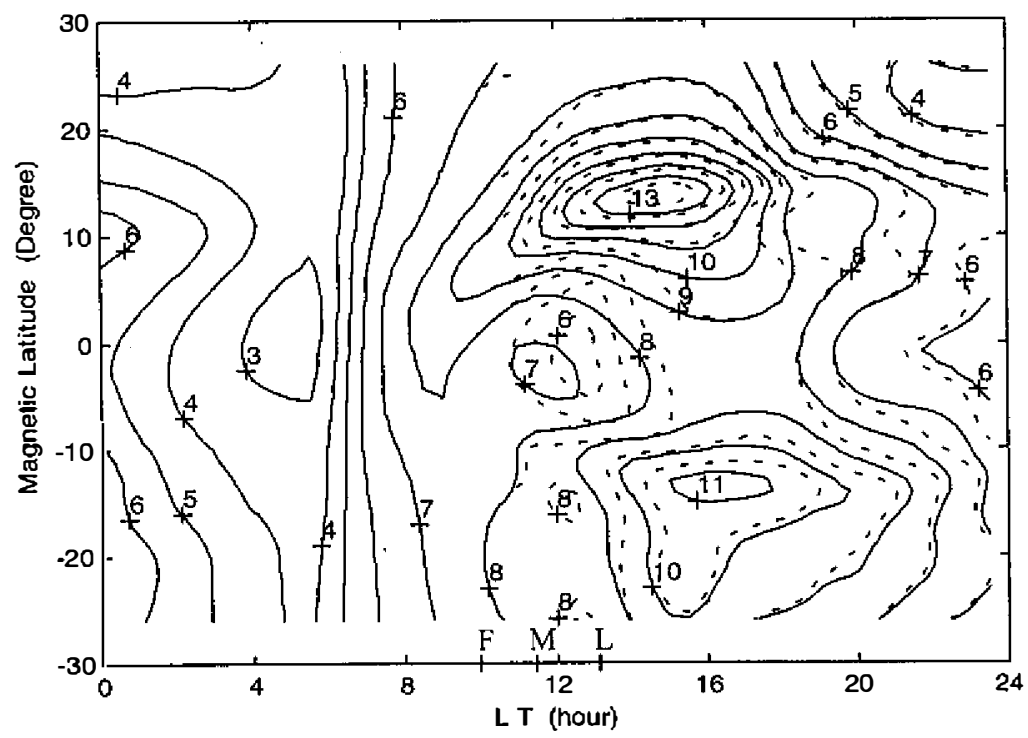

Fig. 3. Contours of calculated $\mathrm{f}_{0} \mathrm{~F}_{2}$ in the control case (with solid lines) and in the eclipse case (dotted lines) within a magnetic longitude of $179^{\circ} \mathrm{E}$. The three short lines F, M and $\mathrm{L}$ on the bottom scale mark the local times of the first contact, the maximum phase and the last contact of the solar eclipse of October 24, 1995 for Hainan station (geographic $110^{\circ} \mathrm{E}, 20^{\circ} \mathrm{N}$ ). 

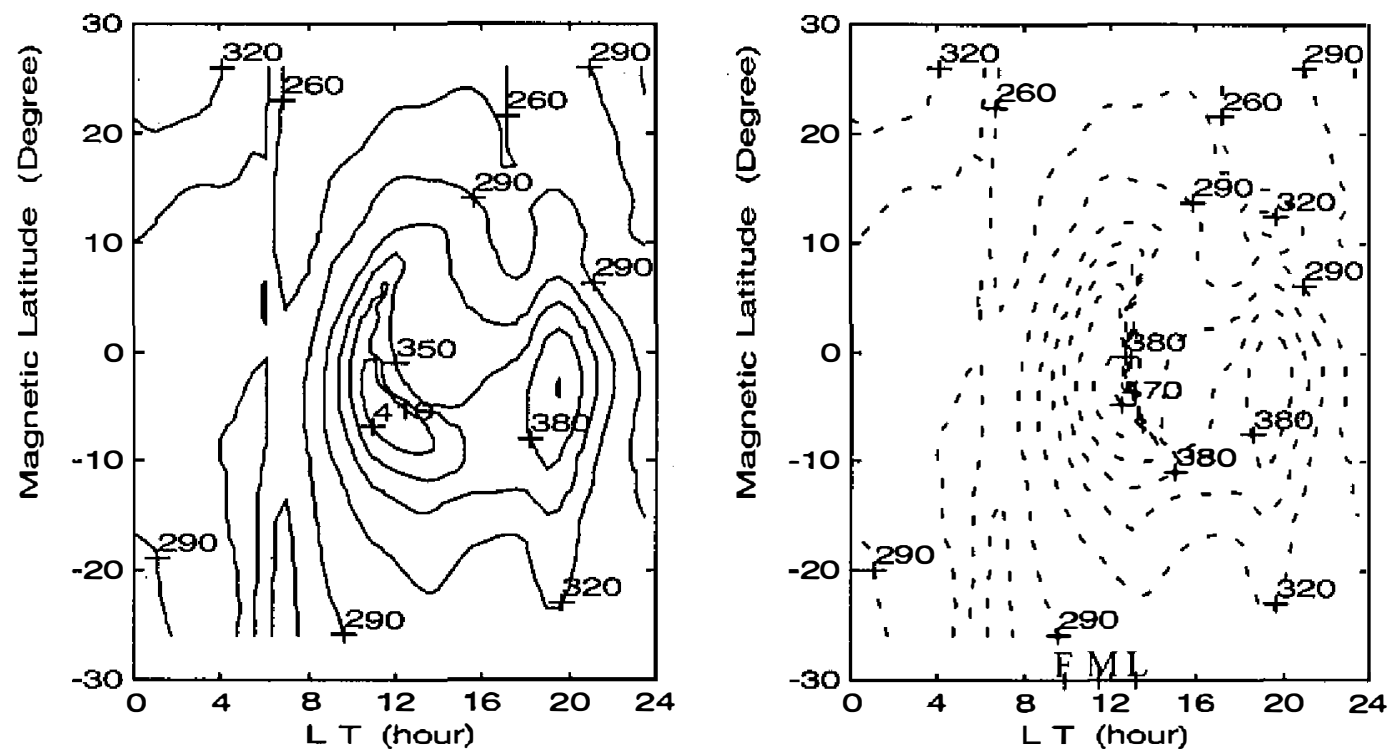

Fig. 4. Contours of the calculated $\mathrm{h}_{\mathrm{m}} \mathrm{F}_{2}$ in the control case (left panel) and in the eclipse case (right panel) within a magnetic longitude of $179^{\circ} \mathrm{E}$. The three short lines F, M and L on the bottom scale mark the same as Fig. 3.

the maximum decrease in $\mathrm{f}_{\mathrm{o}} \mathrm{F}_{2}$ was larger than $2 \mathrm{MHz}$. The following characteristics are clearly noted in the above figures:

(1) After the first contact of the lunar shadow on the Sun, the electron densities on the eclipse condition were lower than those on the control days. In the course of the eclipse, the optical eclipse effects were distinct in the height profiles of the electron densities at lower altitudes of the ionosphere (Figs. 6 and 7). At about 1000 LT, the eclipse first started at geographic latitude $20^{\circ} \mathrm{N}$, then it expanded to other latitudes (see Fig. 2). Following the eclipse, the concentration of electrons in the lower altitudes varied rapidly with the eclipse function $E(\vec{r}, t)$. Compared to those on the control day, the densities of the electrons in this region decreased to a minimum shortly after the maximum phase. Then the densities increased to the normal level with the increase in the solar eclipse function. With the increasing altitude the response to the eclipse slowed down, but it lasted longer than that noted at lower heights. This is consistent with findings from previous eclipses (Sterling and Hanson, 1970).

(2) Compared to those in the control case, the values of $\mathrm{f}_{0} \mathrm{~F}_{2}$ in the low latitudes decreased after the eclipse occurred, and eventually recovered to the normal level after the last contact. At around $1230 \mathrm{LT}$, the largest decrease in $\mathrm{f}_{0} \mathrm{~F}_{2}$ appeared near the geographic latitude of $10^{\circ} \mathrm{N}$, i.e., near the magnetic equator, where the centre of the eclipse was located. At higher magnetic latitudes, the depression in $\mathrm{f}_{0} \mathrm{~F}_{2}$ was smaller. The response to the eclipse lasted longest near the latitude of Hainan, and the decrease remained even a few hours after the last contact.

(3) Throughout the duration of the eclipse, the values of $h_{m} F_{2}$ in the eclipse case, were generally 

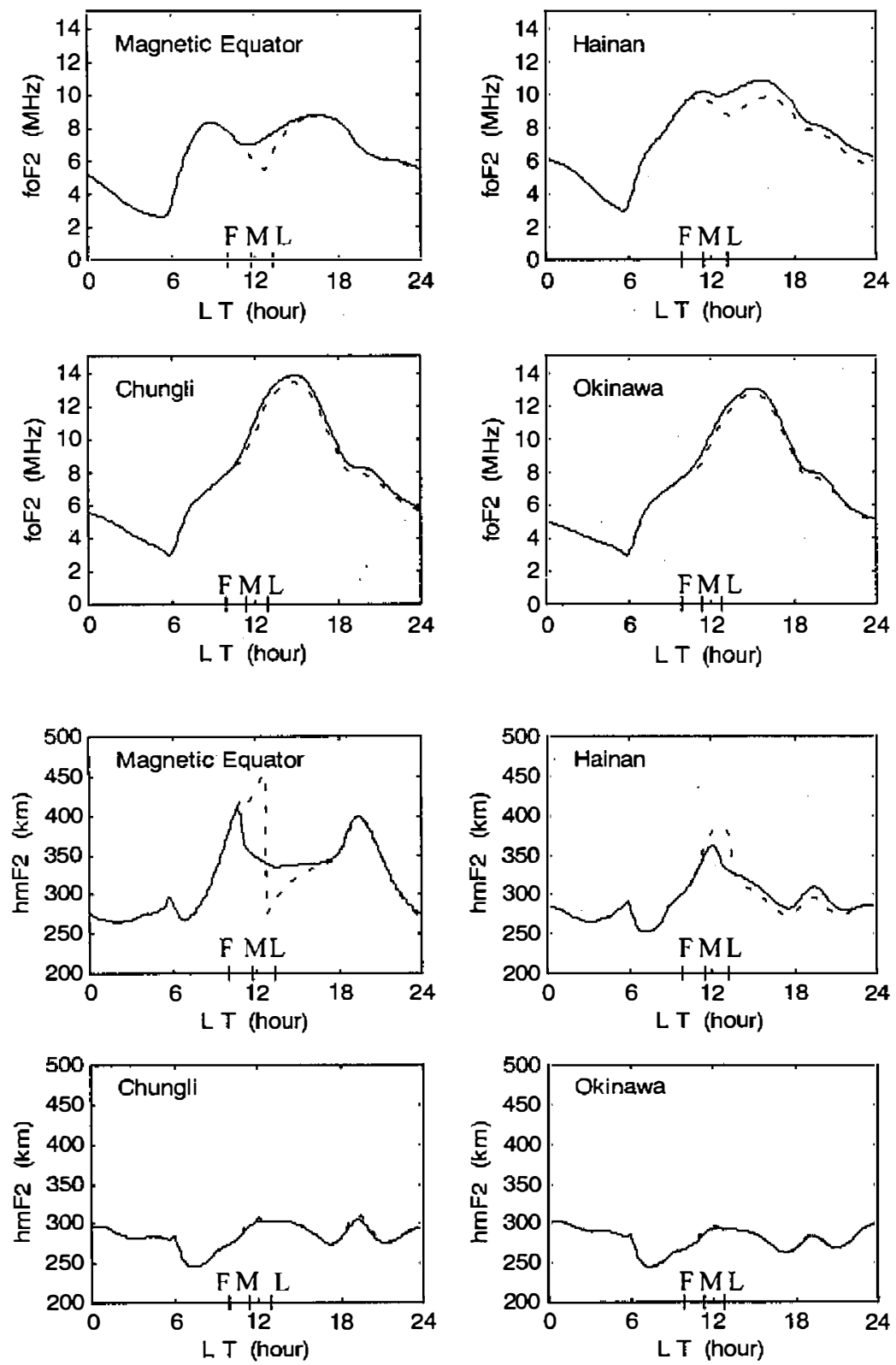

Fig. 5. Calculated $\mathrm{f}_{\mathrm{o}} \mathrm{F}_{2}$ and $\mathrm{h}_{\mathrm{m}} \mathrm{F}_{2}$ on the control day (with solid lines) and on the eclipse day (dotted lines) at some latitudes within a magnetic longitude of $179^{\circ} \mathrm{E}$. The three short lines F, M and $\mathrm{L}$ on the bottom scale mark the respective times of the first contact, the maximum phase and the last contact of the solar eclipse of October 24, 1995 for some latitudes. Stations shown in the figures are represented by their latitudes, i.e., magnetic $0^{\circ}, 8.2^{\circ} \mathrm{N}, 13.6^{\circ} \mathrm{N}$ and $15.3^{\circ} \mathrm{N}$, respectively. 

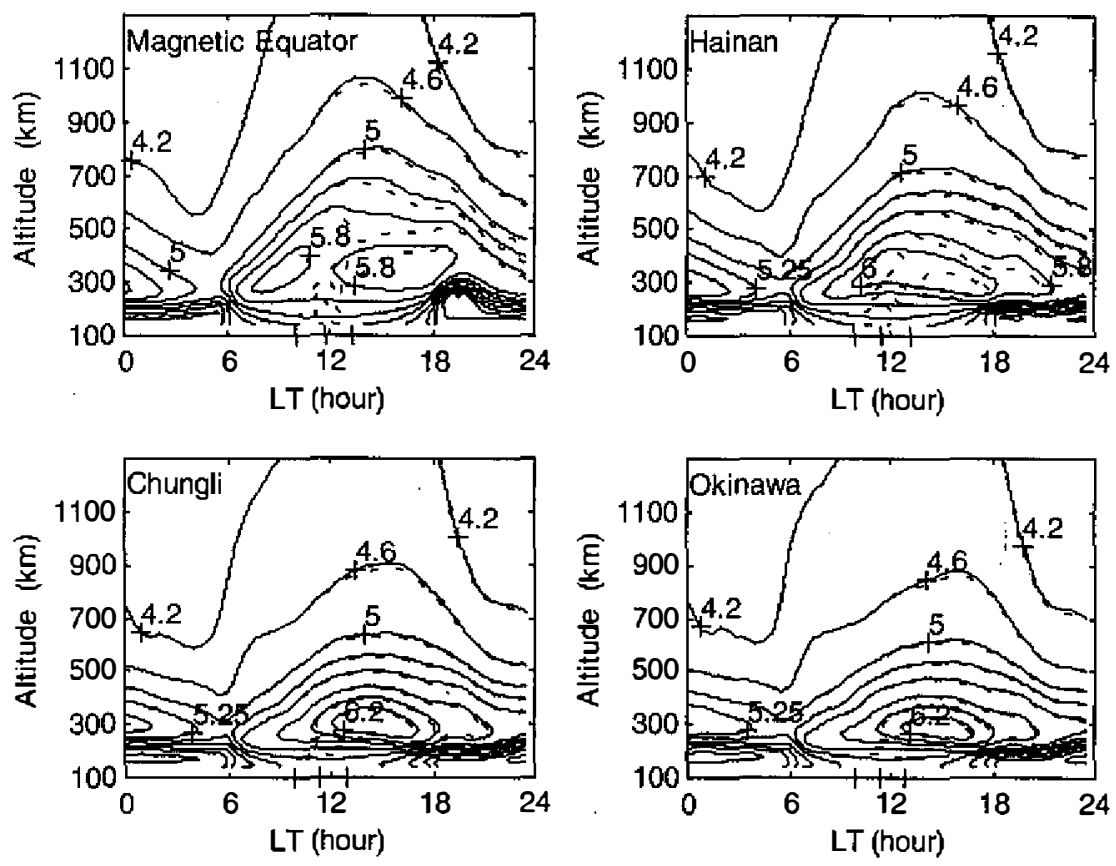

Fig. 6. Same as Fig. 5 but for the logarithm electron densities as the function of height and local time. The unit of electron density is $\mathrm{cm}^{-3}$. Stations shown in the figures are represented by their latitudes, i.e., magnetic $0^{\circ}, 8.2^{\circ} \mathrm{N}$, $13.6^{\circ} \mathrm{N}$ and $15.3^{\circ} \mathrm{N}$, respectively.

higher than those in the control case. The increase in $\mathrm{h}_{\mathrm{m}} \mathrm{F}_{2}$ in the former was the result of variations in ionic production during the eclipse which distorted the height profile of the electron densities. The elecron densities decreased faster at lower altitudes than at higher ones even in the F region during the solar eclipse (Figs. 6 and 7); thus, the peak in the F region was somewhat elevated. Near the magnetic equator (the latitude extent was approximately $\pm 8^{\circ}$ geomagnetic latitude) there was a sharp ransition in $\mathrm{h}_{\mathrm{m}} \mathrm{F}_{2}$ after the maximum phase (see Figs. 4, 5 and 7) due to the appearance of another peak below the normal $F$ layer (Fig. 7).

(4) After the maximum phase there were two peaks in the F layer in the height profile of the densities of electrons near the magnetic equatorial region (Fig. 7). This phenomenon is known as the equatorial eclipse $\mathrm{F}_{1.5}$ layer (Ledig et al., 1946).

\section{DISCUSSION AND CONCLUSIONS}

This study presents some modelling results of the response of the ionosphere to the October 24,1995 solar eclipse near about the geographic $110^{\circ} \mathrm{E}$ longitude sector, i.e., magnetic longitude $179^{\circ} \mathrm{E}$. 

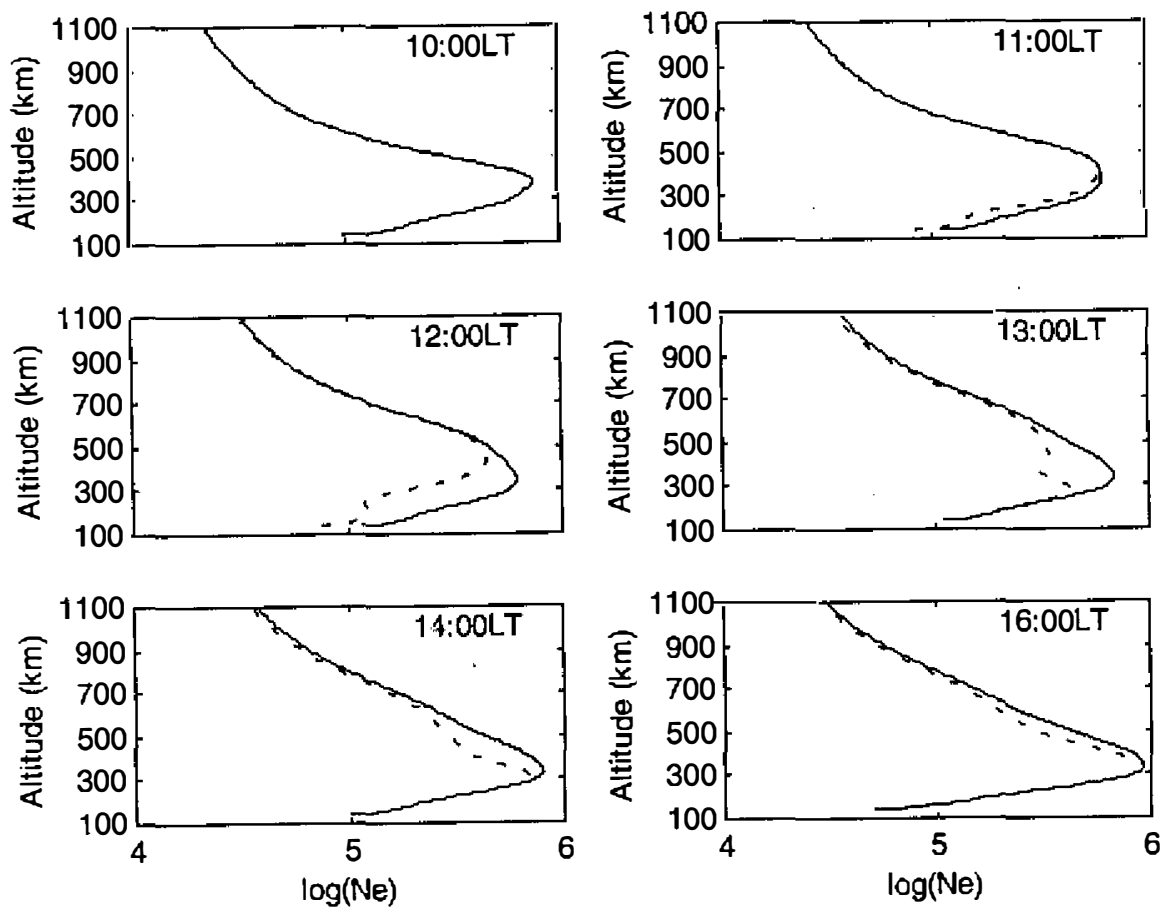

Fig. 7. Height profiles of logarithm electron densities at some local times above the magnetic equator. The electron density is in $\mathrm{cm}^{-3}$. Solid curves are for the normal case, and dotted lines for the eclipse case.

A solar eclipse may bring about some complex phenomena (e.g. Li et al., 1990; He and Long, 1990), like travelling ionospheric disturbances (TIDs) and an equatorial eclipse $F_{1.5}$ layer, by changing the temperature and motion of the atmosphere and by altering the electric conductivity of the ionosphere, etc. It is well known that a solar eclipse decreases the electron density in the $\mathrm{E}$ and low $\mathrm{F}_{1}$ regions ( $\mathrm{Li}$ et al., 1990), but the situation of the $\mathrm{F}$ layer is more complex (He and Long, 1990). It is reported that the behaviour of both the maximum densities and peak heights of the $\mathrm{F}$ layer vary from eclipse to eclipse and from one place to another (e. g. He and Long, 1990; Evans, 1965; Li et al., 1990). In the afternoon of the July 4, 1963 eclipse at Millstone Hill, compared with control day, the values of $\mathrm{f}_{\mathrm{o}} \mathrm{F}_{2}$ were larger and the $\mathrm{h}_{\mathrm{m}} \mathrm{F}_{2}$ was 20-30 km higher (Evans, 1965). During the period of the eclipses in April 1958 and in March 1988, the $\mathrm{h}_{\mathrm{m}} \mathrm{F}_{2}$ at Hainan and at Guangzhou was 50-100 km higher, and $\mathrm{f}_{0} \mathrm{~F}_{2}$ at Hainan (geographic $19.5^{\circ} \mathrm{N}$ ) and at Guangzhou (geographic $23.1^{\circ} \mathrm{N}$ ) was larger than on the control days. With the annular eclipse of September 23, 1987, the $h_{m} F_{2}$ at Hainan and at Guangzhou was 20 $\mathrm{km}$ lower, while $\mathrm{f}_{0} \mathrm{~F}_{2}$ at Hainan matched that on the reference day. The $\mathrm{f}_{0} \mathrm{~F}_{2}$ at Guangzhou was also larger (He and Long, 1990).

In this paper the calculations under eclipse conditions only considered the variations in solar EUV fluxes due to the lunar shadow during the eclipse. Results presented in the above section show decreases in $\mathrm{f}_{0} \mathrm{~F}_{2}$ and lifts in the $\mathrm{h}_{\mathrm{m}} \mathrm{F}_{2}$ in the eclipse case compared with the 
reference case. The results simulate well the characteristics of electron densities in the $\mathrm{E}$ and lower $F_{1}$ layers during the eclipse. Using $\mathrm{f}_{\mathrm{o}} \mathrm{F}_{2}$ measured from six stations in the equatorial anomaly region during the same eclipse, Yeh et al. (1997) identified three large-scale effects. Two of them may be related to the eclipse (Huang et al., 1999). The results of the present study show a secondary depression in $\mathrm{N}_{\max }$ for latitudes lower than geomagnetic $14^{\circ} \mathrm{N}$, but the maximum depression in $\mathrm{N}_{\max }$ near the maximum obscuration region was not observed by Yeh et al. (1997). Nevertheless, this is clearly shown in another observation (see Fig. 4 of Huang et al., 1999). The enhancement of $\mathrm{f}_{0} \mathrm{~F}_{2}$ before the maximum phase at approximately geomagnetic latitude $7-10^{\circ} \mathrm{N}$ at $275-300 \mathrm{~km}$ height (Huang et al., 1999) and the increase in $\mathrm{N}_{\max }$ for the region higher than geomagnetic latitude $20^{\circ} \mathrm{N}$ (Yeh et al., 1997) do not appear in the present modelling results either. This indicates that other factors compensate for the depression in $\mathrm{N}_{\max }$ due to the decrease in solar EUV fluxes during the eclipse, i.e. if the increase in $\mathrm{N}_{\max }$ and electron densities at $275-300 \mathrm{~km}$ altitude before the maximum phase is not due to day-to-day variations. The vertical $\boldsymbol{E} \times \boldsymbol{B}$ drift can induce this effect according to another one of our simulations which adjusted vertical $\boldsymbol{E} \times \boldsymbol{B}$ drift (Liu et al., 1999). Further study of the ionospheric effects in the $\mathrm{F}$ region and high ionosphere should focus more closely on the responses to other factors, like $\boldsymbol{E} \times \boldsymbol{B}$ drift, gravity waves and neutral winds, for such variations may be related to the eclipse. In addition, because the observed data on the $h_{m} F_{2}$ were not collected and there was no station near the magnetic equator, a comparison between the observed and simulated $\mathrm{h}_{\mathrm{m}} \mathrm{F}_{2}$ can not be made here.

Around the magnetic equator region an equatorial eclipse $F_{1.5}$ layer cusp, i.e. two peaks in the height profile of the electron density in the $250-600 \mathrm{~km}$ altitude region, was observed in our results. The eclipse $F_{1.5}$ layer near the center of the eclipse was reported for previous eclipses (Ratcliffe, 1956; Sterling and Hanson, 1970; Van Zandt et al., 1960). The eclipse of October 24, 1995 was a low latitude one with its center near the magnetic equator. From Fig. 7 we can clearly see the formation of the eclipse $F_{1.5}$ layer. After the first contact with the eclipse, the electron density in the $E$ and $F_{1}$ layers decreased rapidly with the depression of the solar EUV fluxes due to the eclipse shadow effects. During the daytime, an upward drift was observed at equatorial and low latitude regions on geomagnetic quiet days (i.e. Fejer, 1981). Under the upward force of the vertical drift lifts, charged particles in the bottom side of the ionosphere moved upward. The electron in the $\mathrm{E}$ and $\mathrm{F}_{1}$ regions tended to recover to the normal level of the reference day after the maximum phase, but the $\mathrm{F}$ layer responded later. A fovea was gradually formed in the height profile of the electron density under the influence of upward drifts and the different photochemical relaxation times of altitudes. Under the effect of upward vertical drift, the position of the fovea and the normal $F$ layer peak also moved upward. Due to the longer photochemical relaxation characteristic time at higher altitudes, a new peak or cusp appeared in the height profile of the electron density in the $F$ layer under the fovea. After the last contact, the electron density in the $\mathrm{F}$ layer gradually increased to the normal level of the reference day, and the fovea became smaller. Therefore, two peaks in the $\mathrm{F}$ region finally merged, and the eclipse $\mathrm{F}_{1.5}$ layer disappeared.

Ratcliffe (1956) pointed out that the eclipse $F_{1.5}$ layer could be caused by an increase in the height of the photochemical relaxation time of the ionosphere; however, Sterling and Hanson (1970) explained the $\mathrm{F}_{1.5}$ layer in terms of the electrodynamical drift. When we set the drift to 
zero, no $\mathrm{F}_{1.5}$ cusp appeared in our results (Figures not shown) as indicated by Sterling and Hanson (1970). It should also be pointed out that with the same drift model our calculations for the reference case did not produce an $F_{1.5}$ cusp (Fig. 7). From the calculations mentioned above, the vertical drift played an important role in the formation of the equatorial eclipse $F_{1.5}$ layer, but the shadow effects of the EUV fluxes by the moon and the difference in the photochemical relaxation time with height in the ionosphere were also necessary factors.

In summary, the ionospheric responses to the depression of the solar EUV fluxes during the eclipse were investigated in this paper. As mentioned in the beginning of this section, a solar eclipse induces very complex phenomena. Results in this paper can not reflect all of the eclipse-related effects during this eclipse, except for the secondary depression in $f_{0} F_{2}$ at a few hours after the maximum phase. The observation by Yeh et al. (1997) revealed that the largest depression of $\mathrm{N}_{\max }$ appeared at around geographic $14^{\circ} \mathrm{N}$, even though the obscuration was large at latitudes lower than $14^{\circ} \mathrm{N}$. However, the calculations indicate that the lower the latitude, the larger the depression. What caused the difference between the calculations and the observation? What is implied is that other effects were mainly a result of other processes related to the eclipse, not mainly or directly by the depression of the ion and electron photoionization production rates.

Acknowledgments The authors would like to thank two reviewers for their helpful suggestions and comments to improve the manuscript. This research is supported by the National Natural Science Foundation of China (49804008).

\section{REFERENCES}

Anderson, D. N., 1981: Modeling the ambient, low latitude F-region ionosphere-a review. $J$. Atmos. Terr. Phys., 43, 753-762.

Bailey, G. J., and R. Sellek, 1990: A mathematical model of the earth's plasmasphere and its application in a study of $\mathrm{He}+$ at L=3.0. Ann. Geophysciae, 8, 171-190.

Bilitza, D., 1990: International reference ionosphere 1990, NSSDC/WDC-A-R\&S, 90-92.

Evans, J. V., 1965: An F region eclipse. J. Geophys. Res., 70, 131-142.

Fejer, B. G., 1981: The equatorial ionospheric electric fields, A review. J. Atmos. Terr. Phys., 43, 377-386.

Fraser-Smith, A. C., 1987: Centered and eccentric geomagnetic dipoles and their poles, 16001985. Rev. Geophys., 25, 1-16.

He, You-Wen, and Qi-Li Long, 1990: The ionospheric effects of the solar eclipse. ACTA Geophysica Sinca, 33, 373-383(in Chinese).

Hedin, A. E., 1987: MSIS-86 thermospheric model. J. Geophys. Res., 92, 4649-4662.

Hedin, A. E., M. A. Biondi, R. G. Burnside, G. Hernandez, R. M. Johnson, T. L. Killeen, C. Mazaudier, J. W. Meiwether, J. E. Salah, R. J. Sica, R. W. Smith, N. W. Spencer, V. B. Wickwar, and T. S. Virdi, 1991: Revised global model of thermosphere winds using satellite and ground-based observations. J. Geophys. Res., 96, 7657-7688.

Hewett, D. W., and A. B. Langdon, 1987: Electromagnetic direct implicit plasma simulation. 
J. Computation Physics, 72,121-155.

Huang, C. R., C. H. Liu, K. C. Yeh, K. H. Lin, W. H. Tsai, H. C. Yeh, and J. Y. Liu, 1999: A study of tomographically reconstructed ionospheric images during a solar eclipse. $J$. Geophys. Res., 104, 79-94.

Ledig, P. G., M. W. Jones, A. A. Giesecke, and E. J. Chernosky, 1946: Effects on the ionosphere at Huancayo, Peru, of the solar eclipse, January 25, 1944. Terr. Magnet. Atmos. Elec., 51, 411-418.

Li, Li-Bin, Wan Wei-Xing, Wu Zhen-Hua, and Li Jun, 1990: Ionospheric disturbances during the annular eclipse of September 23, 1987. ACTA Geophysica Sinica, 33, 384-390 (in Chinese).

Liu L.-B., J.-N. Tu, and Z.-T. Bao, 1998: Effects of neutral winds on the nighttime lowlatitude ionosphere. Chinese J. Space Physics, 18, 308-312 (in Chinese).

Liu L.-B., W.-X. Wan, J.-N. Tu, and Z.-T. Bao, 1999: Modeling study of the ionospheric effects during the solar eclipse of October 24, 1995. Chinese J. Space Physics, 19, 200205 (in Chinese).

Mitra, A. P., 1968: A review of D-region process in non-polar latitudes. J. Atmos. Terr. Phys., 30, 1065-1114.

Sterling, D. L., and W. B. Hanson, 1970: Calculations for an equatorial F2-region solar eclipse. Radio Science, 5, 1029-1039.

Sterling, D. L., W. B. Hanson, and R. F. Woodman, 1972: Synthesis of data obtained at Jicamarca, Peru, during the September 11, 1969 eclipse. Radio Science, 7, 297-289

Tobiska, W. K., 1991: Revised solar extreme ultraviolet flux model. J. Atmos. Terr. Phys., 53, 1005-1018.

Torr, M. R., and D. G. Torr, 1982: The role of metastable species in the thermosphere. Rev. Geophys. Space Phys., 20, 763-774.

Tu, J.-N., L.-B. Liu, and Z. T. Bao, 1997: A low latitude ionospheric theoretical model. Chinese J. Space Physics, 17, 212-219 (in Chinese).

Van Zandt, T. E., R. B. Norton, and G. H. Stonehocker, 1960: Photochemical rates in the equatorial F2 region from the 1958 eclipse. J. Geophys. Res., 65, 2003-2009.

Yeh, K. C., D. C. Yu, K. H. Lin, C. H. Liu, C. R. Huang, W. H. Tsai, J. Y. Liu, J. S. Xu, K. Igarashi, C. Xu and W. Wan, 1997: Ionospheric response to a solar eclipse in the equatorial anomaly region. Terr. Atmos. Oceanic Sci., 8, 165-178. 